\title{
Contributions of the Department of Engineering Sciences of the Bulgarian Academy of Sciences in Automation, Robotics and Computers during the Past Century
}

\author{
Vassil Sgurev \\ ${ }^{1}$ Institute of Information and Communication Technologies, Sofia, Bulgaria \\ Emails:sgurev@bas.bg
}

\begin{abstract}
Technical, at the time called "positive" sciences take their place in Bulgarian Academy of Sciences (BAS) relatively late: at the end of the 19-th century and at the beginning of the 20th century. Then for first time their representatives are elected for full BAS members. Only in 1959 a state act forms the Department of Technical Sciences (DTS) as a self-dependent structural division within the range of the academy. Regardless of this delay the department succeeds very fast to realize significant achievements in the realized in the country industrialization and in particular - in the high-tech production. In DTS-BAS appear the first for our country scientific teams in the field of automation and cybernetics. The first automated systems and also the first Bulgarian system with a specialized computer and periphery for a real-time control of an industrial transport have been started and implemented there. Noteworthy are the successes of technical sciences in the field of initiation, development and the rapid and broad development of the serial production and distribution of the personal computers as a new highly efficient trend in the information technologies. Following an analogical scenario the technical sciences in Bulgaria initiated the research in the field of robotics the result of which was the industrial production and the implementation of industrial robots. All this to a considerable extent helped the creation and the development of hightech production in Bulgaria during the past century
\end{abstract}

Keywords: Technical sciences, Academy, Robotics, Computers, Achievements. 


\section{Overview of the contributions of the unit of engineering sciences at BAS in automation, robotics, and computers during the past century}

In 1959, 90 years after the establishment of the Bulgarian Literary Society (BLS) the Council of Ministers takes the decision published in Decree No 236 from November 3, 1959 about the creation in the Bulgarian Academy of Sciences (BAS) of a Department of Technical Sciences (DTS) aiming at 'the further development of the Bulgarian science and the increase of its role in the socialist construction'. The first Academic secretary of the DTS at the Bulgarian Academy of Sciences has been elected Correspondent Member Angel Balevski [2].

The establishment of the Department of Technical Sciences at the Bulgarian Academy of Sciences is not an accidental idea of a high-ranking state officer. It is based on the accepted state policy - after the completion of the post war reconstruction period, to accelerated industrialization and modernization of the individual sectors of the economy. The goal is to catch up with the leading countries, the task - long-lasting and difficult to solve.

The Presidium of the Bulgarian Academy of Sciences reacts quickly and at its meeting on November 20, 1959, it determines the structure of the new department with the main directions in which it will develop and the necessary means for this development. On the basis of the taken decisions, in the following years the following fields of technical sciences will be found at the DTS-BAS: automation and cybernetics; metal casting and metalworking; building mechanics; research and management of water resources.

In the years after 1959, various scientific units, laboratories and institutes have been set up and reorganized in which activities will be carried out on the above mentioned four strands.

This paper describes the achievements of DTS in one of four directions: scientific and applied results on metal casting and metalworking, structural mechanics and water resource management research and management are the subject of other investigations. Achievements in computer technology are in practice related to all other departments of the academy.

The department "Relay Protection and Automation of Energy Systems", headed by Assoc. Prof. Bojidar Popov, is set up in this slant to the existing Institute of Power Engineering (IPE) at the Bulgarian Academy of Sciences directed by Assoc. Prof. Eng. Georgi Rasheev.A separate department has been formed at DTSBAS 'Automation and Telemechanics', headed by Assoc. Prof. Eng. Denyo Belchev. It follows from these facts that in 1959 there have been foresight in the academy and the development of the high-tech direction 'automation' was planned. Institutionally, this outpaces the establishment of the Automation Central 
Laboratory (ACL) and the Central Research Institute for Complex Automation (CRICA).

In 1962, the two automation units have been reorganized in the unified department 'Automation and Telemechanics' with Compatibility Director Assoc. Prof. Eng. Georgi Rasheev, while retaining the same subject. In August 1963 it was transformed into the Central Laboratory of Automation and Telemechanics (CLAT) at the Bulgarian Academy of Sciences, headed by Assoc. Prof. Eng. Nikolay Naplatanov, who is a Compatibility Head of the Department of Industrial Automation at the Mechanical-Electrical Engineering Institute (MEEI) Sofia. It is comprised of 40 associates and with the following two departments: 'Technical Instruments for Automated Control, Regulation and Management', headed by Assoc. Prof. Eng. Deniu Belchev and 'Systems for Centralized and Telemechanical Control and Management', headed by Assoc. Prof. Eng. Bojidar Popov.

There is an active preparatory activity for the establishment of the Institute of Technical Cybernetics (ITC) at the Bulgarian Academy of Sciences, based on the ACL-BAS. The consultant in the establishment of the institute is Prof. B. Sotskov Corresponding Member of the Academy of Sciences (AS) of the USSR.

On April 1, 1964, the Presidium of the Bulgarian Academy of Sciences approves the establishment of ITC at the Bulgarian Academy of Sciences with the following sections: Applied Mathematical Problems of Technical Cybernetics (AMPTC), headed by Assoc. Prof. Dr. N. Naplatanov, Elements and Tools of Technical Cybernetics (ETTS), led by Assoc. Prof. Eng. D. Belchev, System for Central and Telemechanical Control and Management (SCTCM), headed by Eng. F. Velkov, Automated Control and Regulation Systems (ACRS) with Assoc. PROF. Eng. B. Popov and Bionics, headed in compatibility by Assoc. Prof. Dr. A. Gidikov.

Assoc. Prof. Dr. N. Naplatanov has been elected as the Director of ITC-BAS, and as Scientific Secretary - Eng. P. Petrov. The last change in the structure of this institute was in 1978 when its leadership consisted of the director Corresponding Member Prof. N.Naplatanov, the deputy directors Assoc. Prof. Dr. I. Popchev and Prof. DSc. D. Mladenov, and the scientific secretary Assoc. Prof. Dr. V. Sgurev. The departments are now eight and they have the following names: Applied Mathematical Problems of Technical Cybernetics (AMPTC), headed by Assoc. Dr. I. Popchev, Ergonomic Management Systems, headed by Corresponding Member Prof. N. Naplatanov, Management of Industrial Systems, headed by Assoc. P. Petrov, Informatics, headed by Assoc. Prof. Z. Nikolov, Bionics, headed by Correspondent Member Prof. N. Naplatanov, Automation of Intellectual Activity, headed by Assoc. Prof. Dr. V. Sgurev, Information Transmission Systems, headed by Assoc. Prof. F. Velkov and Hybrid Modeling, headed by Prof. DSc. M. Zlatev. The Institute has two subsidiary units: Hybrid Computing Complex (HCC), headed 
by Assoc. Prof. N. Milev and Development and Implementation Base, led by Eng. K. Kurshumov.

For almost its 20 years existence from the establishment of the Department of Technical Sciences, until 1978, when a large-scale reorganization of ITC-BAS has taken place, quite a number of theoretical investigations have been carried out and a number of systems and devices have been created, some of which have been implemented in practice. They enable the Department of Technical Sciences to take a prominent place in the academy and beyond in automation, cybernetics, robotics and computer technology. It is not possible to describe these achievements in detail in a single article, but the more important of them are worth mentioning. Such are: The System for Automated Measurement and Regulation of Molding Mist Humidity (1961), The Complex Tele-mechanical System TP-62 for Constructing Automation Technical Devices (1965), The Electrocardiogram Rhythm Analysis Method and Device ANDROS-66 (1966), The Electronic Diagnostic Machine EDM-4 (1967), the production of ANDROS-R by the "Electronics" Plant (1967), the Technical Diagnostics Fluid-Elements System (1967), the PH-Meter (1967), The Liquid Electrical Conductivity Meter CONDUCTOMETER (1968), the Fluid Jet Elements System (1969), the System of Software and Technical Devices for the Management of Freight Transport in Mining and Quarrying Plant "Medet" Astra 71 (1970), The Transmission System for Operative Statistical Information CENTRONIC-1001-TC (1970), the Managing Computing Machine with Integrated Circuits Astra 71-25 (1972), the implementation of the Astra 71 Industrial Transport Operative Management System in Mining and Quarrying Plant "Medet" (1973), a range of Hydraulic Jet Elements FALOMA (1973), the Screening Diagnostic Information System of the Ministry of Public Health (1973 г.), the INTERTEST Automaton for Functional Control and Diagnostics of Devices with Integrated Circuits (1973), the Algorithms and Programming Systems for Optimal Distribution of Water Resources (1975), the Design Automation System SAPR (1976), the Multi-Dimensional Adaptive Systems (1977), the Complex of Systems for Managing a Class of Mobile Objects VISEUR (VIEWFINDER, 1977), The Adaptation of Early Diagnostics of Cancer Systems (1977), The Development of a Class of Multi-Microprocessor Management Systems (1978), the Human-Machine System EXATEST (1978), The Automated Operative Management System (AOMS) of the Technological Transport in Copper Extraction Plant "Elatzite" (1978).

Some of these developments have not been implemented, but - with all their criticism as a whole - it must be noticed that, first, their number impresses, and secondly, that they are the first and very often successful attempts to entry into important areas of information technologies that are actively developing today.

The Astra 71 system for operational management of industrial road transport in Mining and Quarrying Plant (MQP) "Medet" deserves special attention. For this 
purpose the first Bulgarian specialized computing machine for real-time operation has been created with incredible difficulties. The development and deployment of this computer control configuration has been entirely done by a team of ITC-BAS in the period 1970-1974. For those years, at that time, the development, training of operating personnel and the deployment of such system has required too much time, patience, persistence and skills to overcome enormous difficulties. Researchers and developers have had these qualities and this enabled the Astra 71 system to work successfully for 12 years - until the resources of the mine have been exhausted and its closure. With numerous patents and efficient solutions, as well as the successful operation of the system, Astra 71 has taken a lead in similar systems outside of our country.

Mining and quarrying specialists have closely followed the vicissitudes of the implementation of the system and this helped accelerate the use of electronic computing devices in industry.

These developments are based on relevant theoretical research, the most significant of which are the following: Methods and Algorithms for Synthesis of Recognizing Diagnostic Systems (1968), Research of the Hierarchical Structure of Managing Large Systems (1968); Methods and Algorithms for Operative Management of Industrial Transport Systems in Real Time (1971); Methods and Technical Tools for Presenting Navigational Information for Piloting Unmanned Controlled Flying Objects (1973); Approach for Optimal Synthesis of a Specialized Digital Computing Machine (DCM) (1974); Algorithms and Programs for Optimal Distribution of Water Resources (1976); Closed Transport Systems Description Method (1976); Synthesis of Automata in a Homogeneous Environment (1976); Method-Oriented Programming (1976); Multidimensional Adaptive Systems (1977); Research and Synthesis of Multi-Microprocessor Management Systems (1978).

ITC at BAS has organized a number of international conferences: Applied Aspects of Automata Theory (Varna, 1970); International Conference on Fluidics (Varna, 1972); Optimization of Systems for Collection, Transmission and Processing of Analogous and Discrete Information in Local Information Networks (Minsk, 1976); Information Processing and Transmission Systems (1977); Design Automation Systems (DAS) (VGS-2, Sofia, 1977).

In 1963, the academic journal 'ACL-BAS News' has begun to go out, which in 1964 has been renamed "The Engineering Cybernetics Institute's News". In 1964, the Scientific Council of ITC at the Bulgarian Academy of Sciences has received the right to award the scientific title and the grade 'senior research associate (s.r.a. - today Assoc. Prof.) 2-nd grade' and 'candidate in the technical sciences (c.t.s. - today Dr.)".

At the end of 1978 a decision has been made at the highest state level on a radical, profound reorganization of ITC at BAS with the institute focusing on 
solving important national tasks with a practical focus. The leadership of BAS has not been informed of this decision, which has been dropped from above 'for execution'. Later, such practice will be applied to other BAS institutes.

On November 30, 1978 Order No. 73 of the Council of Ministers has been published, which establishes the Institute of Technical Cybernetics and Robotics (ITCR) at BAS on 1 December 1978 on the basis of ITC at BAS and three scientific-research laboratories of the Center for Accelerated Deployment (CAD) "Progress" of the State Committee for Science and Technical Progress (SCSTP), namely, "Unique Electronics", "Specialized Robots" and "Mechanization and Automation of Welding Processes". The purpose of this new academic institute is defined as "experimental and applied research in areas related to cybernetic systems for managing technical processes and objects, research and implementation in the field of robots and their accelerated application in the national economy, experimental production as well as training, preparation and post-graduate qualification of specialists in these fields'.

The text follows mainly in two directions: 'cybernetic systems for management of technical objects and systems' and 'research and development activities in the field of robotics'. For the new institute, there are resources of 600 thousand BGL for the second direction. The assets of ITC-BAS, including the newly built block 2 of BAS pass through to it.

Decisive actions are undertaken - all employees and associates of the old institute are released, but they can participate in the competition for 360 new posts at the new academic institute. Since 1980, the former "Sasho Kofardzhiev" Scales Factory has been given as the Experimental Base by the industry to the ITCR at BAS. The list has reached a total of 870 people.

Assoc. Prof. Dr. Angel Angelov is appointed director, until then DeputyChairperson of the State Committee for Science and Technical Progress (SCSTP), Deputy-Director - Assoc. Prof. Petar Petrov, and Scientific Secretary - Dr. Nikolay Iliev. There are two directions: 'Technical Cybernetics' led by Dr. Nikolay Iliev and "Industrial Robots", led by Assoc. Prof. Nedko Shivarov. The six sections are divided between these directions. Eng. Bogdan Stoyanov has been elected head of the development and deployment units.

With the resources and effort made available, the Experimental Base and Development Units have been transformed into a truly experienced plant (a kind of "techpark", as they would now say). It includes: an electric-constructive assembly; machine-building department; technological documentation and archives; breeding base; electro-assembly workshop for rapid implementation of prototype models, models and experimental installations; unit for the automated design of the experimental plants. Several associates of departmental science and development have joined the ITCR and this has allowed this academic institute to get the same opportunities as the leading industrial institutes. This has allowed ITCR-BAS to 
send in series of production plants verified technical documentation for the manufactured products, which can be immediately used in production.

The activity of development and construction of industrial robots, the electromechanics of which has been produced by the Beroe plant in Stara Zagora, and the control devices from the Disk Storage Devices (DSD) - Stara Zagora, has started very quickly. The specialists from the Institute have participated in the selection and purchase of machinery and equipment, as well as in the selection and training of staff for the "Beroe" plant and the auxiliary workshops working in cooperation with it. The ITCR at BAS has initiated the establishment of a departmental robotics institute in the town of Stara Zagora and has provided significant assistance in its consolidation.

The first task has been to design a microprocessor control unit for the hydraulic robot of the Versatran-AMF series, for which the hydro-mechanical construction has been purchased by the "Beroe" plant. The controller has been embargoed, and its design and prototyping has been carried out in ITCR. The terms have been short and the difficulties have been considerable. Everything has been completed successfully; the factory and ITCR have gained confidence that they can produce even more sophisticated products.

The next much more difficult task has been to design a robotic complex for arc welding (РБ-251). This development is entirely Bulgarian and is protected by several patents. The development has been supported by the Paton Institute of the Ukrainian Academy of Sciences. The Paton Institute and ITCR-BAS have established in Sofia a joint international laboratory 'Interrobosvarka', which has helped greatly to raise the level of robotic welding in both countries.

The RB-251 complex consists of a portal-type robot for arc welding, a welding current source, a water-cooled burner and a number of technological devices. Modern solutions with multiple feedbacks have been used. Until now, this complex remains one of the most complicated and expensive products ever made in Bulgaria and produced by Bulgarian machine building! At the "Beroe" plant in Stara Zagora, 15 RB-251 complexes have been produced for the needs of the USSR's Military-Industrial Complex (MIC). The reviews of their work are very good.

Another successful direction has been the initiation and creation under the leadership of Prof. Nedko Shivarov of the "Robco" robot family. They have a relatively simple mechanical design, but with their multifunctionality they are a good platform for training in schools and universities. And so far, these robots can be seen in some study halls in our country.

On the base of the base structures used have been developed and manufactured 'take-place' robots for the needs of machine building as well as robots for painting. The latter have more sophisticated control devices and software because the robot had to be trained to repeat the painting operations properly. 
By the time of the changes in Bulgaria since 1990, the Stara Zagora plants has had enough orders from Bulgarian and foreign clients for the production of various types of industrial robots. All this has given serious grounds to BAS and its ITCR Institute to acknowledge the decisive contribution to the initiation and creation of the industrial robots industry in our country. In those years, this fact has not been denied by the professional circles in our country and in the Eastern European countries. Following the changes, due to the inappropriate privatization, the two well-equipped Stara Zagora high-tech factories - Disk Storage Devices (DSD) and "Beroe" - have been brought to a destitute position. This is the end of serial production of industrial robots in Bulgaria! New small businesses have been born, which in their own way continue the Bulgarian robotics traditions.

The next major breakthrough in ITCR-BAS is related to the initiation and production of personal computers in our country $[1,5,6]$. The well-known eminent professional engineer Ivan Marangozov, the first in Bulgaria, who has anticipated the prospects of the emerging class of personal computers designed for personal use by the particular user. Through them it is possible to communicate in networks and with other computers. Eng. I. Marangozov has grouped around him a small team of specialists in the computing equipment for creating a Bulgarian personal computer: engineers Georgi Zhelyazkov, Petar Petrov, Boris Vachkov and others. Such a computer has been developed for a short time in 1980. It is called IMCO-2, 8-bit and fully compatible with the best Apple II Plus, DOS 3.2 and Pascal compiler. Success is complete; the leadership of ITCR and especially its director, Assoc. Prof. Angel Angelov, actively support this direction. The Ministry of Education has commissioned 200 copies of IMCO-2 for schools; they are produced in the Experimental Base of ITCR. At the end of 1981, hundreds of IMCO-2 units created in the same Testing Base have been distributed to many institutions and organizations in our country and have made this computer very popular.

The ITCR leadership is looking for a production site of IMCO-2, focusing on the State Economic Holding (SEH) 'Instrumentation and Automation (IA)'. A branch for ITCR is established on the territory of town of Pravets.

SEH "Izot", though late, develops an 8-bit personal computer. In 1982, the State Committee for Scientific and Technical Progress (SCSTP) and two other interested ministries develop a Program for the development of personal computers in the People's Republic of Bulgaria for the period 1982-1985. Resources have been provided for the equipment of the factories and the production of 100000 pieces of personal computers. A precise expertise has been carried out on which of the two types of computers - IMCO-2 or that of SEH "Izot" - to be produced in series. For all indicators, a higher score is given to IMCO-2, which is widely distributed under the name 'Pravets-82'. The Head of the Experimental Base of ITCR, Assoc. Prof. Plamen Vachkov, is appointed Director of the "Pravets" Microprocessor Engineering Complex (MEC) and is also Deputy Director of ITCR-BAS. SEH 'IA' has been transformed into SEH "Microprocessor Engineering", and Prof. A. 
Angelov is appointed Chairman of its Management Board. The wholesome further work of MEC "Pravets" takes place in the close interaction and coordination of its activity with ITCR at BAS.In the middle of 1984, the group of Eng. I. Marangozov developed the 16-bit personal computer IMCO-4, which is fully compatible with the IBM PC-XT computer. SHE "Izot" has developed competing variants, but in the end the computer of ITCR's Eng. I. Marangozov has better performance, and under the name 'Pravets-16' it is produced in series at the "Pravets" Microprocessor Engineering Complex (MEC). In general, all serially produced personal computers in Bulgaria were made by the group of I. Marangozov, the ITCR and the Bulgarian Academy of Sciences in general; this is quite clear even in those years [3]. The production of Pravets is constantly increasing not only because of the demand in Bulgaria, but also because of the export of these computers abroad. The popularity of personal computers "Pravets" is constantly growing and the annual commodity production increased from 8 million BGL in 1983 to 400 million BGL in 1987.

In general, the initiation and creation of the PC manufacturing industry is the third major achievement of BAS in serially manufactured industrial products, counter-pressure casting machines and industrial robots $[3,5]$.

The ITCR-BAS staff also carries out other important theoretical and applied research in the field of automation, robotics, personal computers and information technology. The most important of these are: Planetary wired devices Isolan, Isomodul and Pollinaplan (1978); the Universal Casting Control System (1979); the Microprocessor Industrial Robot Control Device PB-230 (1979); the Electronic System for Sorting Tobacco Sheets "Deltachrom-01" (1979); the Isomatik-TM Transmanipulator Management System (1979); the Automatic Fire Extinguishing System SAP (1979); the Robotic System for Arc Welding in the Plant for Electric Trucks 'September 6-th' PC-501 (1981); the Functional Modules for Building a System and Tools for Information Processing and Automation MIK-68 (1981); the Microprocessor System for Automated Control of the Technological Process in the Concrete Block "Betoncontrol" (1981); the Automated Non-Destructive Magnetic Control System for Physico-Mechanical Indicators of Rolled Ferrous Metals Using a Microprocessor "Microsom" (1981); the Microprocessor "Icar-10" "Flying Scissors" Control System (1981); the Functional Modules for Construction of Tools for Management of Industrial Robots and Aggregate Machines "Isomatik" (1981); the Basic Microprocessor Regulator "MIK-09" (1984); the Uuniversal Ccurrent Source for Welding Current (1984); the MIC-2000-C Continuous-Process Distributed-Management System (1984); Managing a Small Training Robot "Robco" with a Personal Computer (1984); the Standard Robotized Workstation with Industrial Robot PB-232 for Palletizing in the Ceramic Industry (1984); The Robco-01 Training Anthropomorphic Robot (1985); the Automated Welding Process Control with High Frequency Current Sources for Robot Welding (1985); the Portable Personal Computer for Management of Technological Processes (1985); the Portable Info Terminal PIT-01 (1986); the 32-bit Interlab 
Microcomputer System (1986); the Intel Microprocessor Functional Modules for Building Real-Time Management Systems MC-1000 (1986); the Microprocessor System for Processing and Interpretation of Data from Experimental Research "Compex" (1986); the Managing Device for Robot RB-241 and RB-242 (1987); the Tracy-30 Operative Management System of Industrial Traffic for Mining and Quarrying Plant "Assarel" (1987); The Family of Microprocessor Modules for Computing Devices and Automation Systems for the Design of 32-bit VMEHighways (1987); the Professional PC-MIC-16-Turbo and Real-Time Operating System (1987); the Laboratory Data Collection and Processing System CSY-10 (1987); The ESIAA Expert Technical Assessment System (1987); The Universal Controller "Isomatic-1001-UK" (1987); The Personal Computer "Pravets-16A" and "Pravets-8A" (1987); the Intelligent Controller for Control and Process Management, CSY-16 (1987); The Local Area Network for 16-bit PCs (1987); the Local Network Concentrator Linking Single-Circuit Regulators to a Personal Computer (1987); the RISK Emulators (1988), the Family of Power Supply Units for Electric-Truck Robots (1988) The C-16 Compiler (1988); The MIC-2000 System, Implemented in Neftochim, Burgas (1988); The MIC-2000 Management System for Biotechnological Processes (1989); the Integrated Data Collection and Management System for Industrial Processes "Mikroscan-16" (1989); the Power PC Modules (1989); the Application Package "Multipack-II" (1989); the Distributed Mmicroprocessor Ssystems for Ppersonal Aaccess (1990); the NLP-16 Nonlinear Optimization Software Product (1990); the Adaptive Fault-Resistant Distributed Computing Systems (1990); the Industrial PCs for Industrial Applications (1990).

In spite of this far incomplete list of research and development, there are significant efforts of the numerous ITCR staff that have led to a number of economic developments in our country and to significant theoretical results.

During this period, significant work in the field of Artificial Intelligence (AI) has also taken place in ITCR [8]. In this field, the AIMSA international conference, which has so far produced 17 editions of the same, has been initiated.

The institute is also initiator of the international conferences "PersComp" and "RobCon", which have been held in 1985 and 1987, and also the "Yablonka" Fluidic Conference. There is also considerable international cooperation in volume and scope.

ITCR has established a number of branches of the institute in "Pravets" Microprocessor Engineering Complex (MEC), Stara Zagora, Veliko Tarnovo and Plovdiv. It, together with the Bulgarian Standardization Institute (BSI) and the National Production Holding 'Metal Constructions', has participated in the creation of a research and production base ROSSA, as well as in the Bulgarian-Japanese association MEDICOM SYSTEMS.

With the help of BAS, ITCR bought two apartments in Tokyo, Japan, where a joint Bulgarian-Japanese Robot Laboratory and Computer-Based Laboratory began. Work stopped after the 1990 changes. 
ITCR has independently financed and built a residential building and by 1990 there were no employees registered as needing housing in the Institute. Also, ITCR has built a creative home in the mountain above Vladaya. The construction of such a home and the Veleka River on the Black Sea coast has begun.

During the period from October 1982 to the beginning of 1987, the Director, Assoc. Prof. Angel Angelov, has been appointed ambassador of the People's Republic of Bulgaria in Japan and during that period the position of Director of ITCR-BAS has been executed by Prof. Dr. Vasil Sgurev.

The Institute has two deputy directors, two secretaries of science and six scientific fields of application in each of which are positioned groups of six sections. At the head of these relatively independent directions and units are experienced and authoritative developers, researchers and scientists in the ITCR: Assoc. Prof. Dr. Nikolay Iliev, Eng. Ivan Marangozov, Assoc. Prof. Georgy Nachev, Eng. Bogdan Stoyanov, Correspondent Member Angel Angelov, Prof. DTSs. Vasil Sgurev, Assoc. Prof. Nedko Shivarov. ITCR has a specific status in BAS, which gives it considerable flexibility and effectively stimulates the scientific and applied activity. All this allows ITCR to take a special place in the professional backgrounds of focused, fundamental and applied research.

At the end of the 1980's, the authority of ITCR at BAS in the professional and academic community has been incredibly large. A significant number of young professionals and researchers aspire to work in this prestigious academic institute.

After the 1990 changes, the Department of Technical Sciences (DTS) has been joined to other departments in another structure, and ITCR at BAS is divided into five independent academic institutes and a technology center with an experimental base. Over the next few years, the new ITCR institutes have been reorganized a few more times, and their composition and material abilities have sharply decreased. But this is a completely different story that deserves self-study.

ITCR at BAS can be considered as a specific unique project of the Bulgarian Academy of Sciences - as it would be said today, which in general has proved to be very successful and has left a lasting trace in the technical sciences and computer technologies in Bulgaria. In many ways, it has been ahead of its time, for which it not only gathered many approvals, but not a little envy and malice. Its unique and successful experience can help in our country's ongoing efforts to develop hightech industries.

Since 2000, the Department of Engineering Sciences (DES) has been established at the Bulgarian Academy of Sciences, which should be regarded as the successor of DTS at BAS.

The discussion about the role of the technical sciences in Bulgaria during the past century in the field of automation, robotics and computers should include the firm remark that this role is multidirectional and rather effective. This is related most of all to the initiation, the development and the serial production of personal 
computers and industrial robots. It also concerns the creation of computer cybernetic systems for a real-time control of industrial objects.

This activity helps to a great extent the development of high-tech production in Bulgaria during the past century.

\section{References}

1. Angelov, A., Sgurev, V., Petrov, P.: Some aspects of the automation and informatics development at the Bulgarian Academy of Sciences, Technicheska Myssal, XXXI, Anniversary Issue, 14-19, (1994) (in Bulgarian).

2. Petrov, P.: The contributions of BAS institutes for research and production of computer and communication systems, Journal of BAS, vol. 2, pp. 53-62, (2016) (in Bulgarian).

3. Vachkov, P., Boyanov, K., Yanev, K.: Prospects for the development of personal computers in the 'Microprocessor Systems' economic holding, Proc. of PERSCOMP'87, vol. 1, pp. 51-63, (1987) (in Bulgarian).

4. Angelov, A., Kisyov, Y., Iliev, N.: Instrumental systems and computers, Proc. of PERSCOMP '87, vol. 1, pp. 107-111, (1987) (in Bulgarian).

5. Marangozov, I., Petrov, P. Hristov M., Personal computer 'Pravets-8A', Proc. of PERSCOMP'87, vol. 1, pp. 167-171, (1987) (in Bulgarian).

6. Sgurev, V.: State, developed and perspective of personal computers of the 'Pravets' Family, proc. of PERSCOMP'85, vol. 1, (1985) (in Bulgarian).

7. Boyanov, K.: The role of BAS for the development of research and roduction of computer and communication systems. Journal of the Bulgarian Academy of Sciences, vol.2, 48-53, (2015) (in Bulgarian).

8. Sgurev, V.: State of research on artificial intelligence. Journal of BAS, vol.3, (1986) (in Bulgarian). 